\title{
Acute Encephalitis Beyond the Usual in the COVID Era
}

\author{
Priyankar Pal $^{1}$ (1) $\cdot$ Harshita Jagwani $^{1} \cdot$ Anurag Mandal $^{1} \cdot$ Mohini Bhelo $^{1}$
}

Received: 14 April 2021 / Accepted: 18 June 2021 / Published online: 8 July 2021

(c) Dr. K C Chaudhuri Foundation 2021

To the Editor: An 8-y-old female child presented with a history of fever for $10 \mathrm{~d}$, severe headache, and multiple episodes of vomiting. On admission she was delirious; and other than bilateral conjunctival congestion and oral mucositis, remaining clinical examination was noncontributory. In view of acute encephalitis syndrome, she was started on ceftriaxone, acyclovir, and doxycycline.

Investigations revealed $\mathrm{Hb} 6.6 \mathrm{~g} / \mathrm{dL}$, WBC count 13,600 cells/cumm with $75 \%$ neutrophils, platelet count 60,000 cells/cumm, CRP $135.3 \mathrm{mg} / \mathrm{L}$. Serology for dengue, scrub typhus, smear for malarial parasite were negative. MRI brain was normal. Over the next $36 \mathrm{~h}$, drowsiness increased with episodic violent behavior. In view of nonpurulent conjunctivitis, mucositis, thrombocytopenia, and very high CRP, an inflammatory etiology was considered and further tests showed ferritin $358 \mathrm{ng} / \mathrm{mL}$, NT Pro BNP 20,774 pg/mL, D-dimer 5.81, and negative COVID RT-PCR, while COVID $\mathrm{IgG}$ was positive. Echocardiography showed left anterior descending (LAD) coronary aneurysm $(+4.84 \mathrm{Z})$.

She was diagnosed as multisystem inflammatory syndrome in children (MIS-C) and started on IV immunoglobulin (IVIg) $1 \mathrm{~g} / \mathrm{kg}$ with methylprednisolone $10 \mathrm{mg} / \mathrm{kg} / \mathrm{d}$ for 3 $\mathrm{d}$ followed by oral prednisolone $(2 \mathrm{mg} / \mathrm{kg}$ ), which was gradually tapered and stopped. Subcutaneous enoxaparin was also initiated along with low-dose aspirin. Mentation improved and echocardiography after $1 \mathrm{wk}$ showed diminution of LAD aneurysm. CSF was planned but was eventually not done as she improved on immunomodulatory therapy.

Neurological manifestations in SARS-CoV-2 are reported mainly in adults and include encephalitis, meningitis, encephalopathy, stroke, seizures, anosmia [1], possible pathophysiology being direct CNS invasion by the virus [2] However, very few studies describe similar affection with MIS-C [3], and here the encephalopathy is attributed as a feature of systemic inflammatory response.

With the ongoing pandemic in the absence of a known cause, MIS-C should be a differential in patients with febrile encephalopathy and elevated inflammatory markers. Timely institution of IVIg and corticosteroids [4] may be lifesaving.

\section{Declarations}

Conflict of Interest None.

\section{References}

1. Mao L, Jin H, Wang M, et al. Neurologic manifestations of hospitalized patients with coronavirus disease 2019 in Wuhan, China. JAMA Neurol. 2020;77:683-90.

2. Benameur K, Agarwal A, Auld SC, et al. Encephalopathy and encephalitis associated with cerebrospinal fluid cytokine alterations and coronavirus disease, Atlanta, Georgia, USA, 2020. Emerging Infect Dis. 2020;26:26.

3. Abdel-Mannan O, Eyre M, Löbel U, et al. Neurologic and radiographic findings associated with COVID-19 infection in children. JAMA Neurol. 2020;77:1440-5.

4. Feldstein LR, Rose EB, Horwitz SM, et al. Multisystem inflammatory syndrome in U.S. children and adolescents. N Engl J Med. 2020;383:334-6.

Publisher's Note Springer Nature remains neutral with regard to jurisdictional claims in published maps and institutional affiliations.
Priyankar Pal

mailme.priyankar@gmail.com

1 Department of Pediatric Rheumatology, Institute of Child Health, Kolkata, West Bengal 700017, India 